\title{
An epic voyage in the making
}

\section{The plan to drill through the entire oceanic crust is ambitious and exciting, and well worth the expense.}

The exploration of even the outermost fringes of our Solar System has long crossed over from the realm of fantasy to that of reality. But the human quest to explore our planet's interior - magically expressed in Jules Verne's epic A Journey to the Centre of the Earth - lags far behind. Unlike the leap into space, gravity defying as it may be, a voyage into the planet's bowels faces the sheer resistance of drilling through kilometre after kilometre of dense rock.

Human innovation, though, is only fuelled by such challenges. Indeed, penetrating the oceanic crust and traversing the crust-mantle boundary (the Mohorovičić discontinuity, or Moho) is the principal objective of the ambitious Mission Moho initiative, discussed at the September workshop of the Integrated Ocean Drilling Programme (IODP) in Bremen, Germany.

The first attempt at accomplishing this daunting task - made in the 1960s - was unsuccessful, and the hole reached a depth beneath the sea floor of less than $200 \mathrm{~m}$. But it showed that drilling in the deep ocean was possible, and inspired subsequent missions that have managed to drill deeper. The data and insights gained from such projects have radically altered our understanding of the evolution of the oceanic crust and uppermost mantle.

However, so far no deep-sea drill has managed to reach beyond $1.5 \mathrm{~km}$ beneath the sea floor, which is only about one fourth of the typical distance from the sea floor to the Moho. As a result, much of our knowledge about the deeper parts of the oceanic crust and the uppermost mantle comes from observations of slices of oceanic plates that have been shoved on to continents by plate tectonic processes.

But geological exposure is incomplete as a rule, and remnants of the mantle that have ended up on the continents are not pristine. More importantly, the diverse processes that went into the construction and modification of oceanic crust and uppermost mantle cannot be directly observed in such outcrops, but can only be inferred. Drilling through the oceanic lithosphere is expected to fill in the gaps in our understanding of processes ranging from mantle melting to hydrothermal alteration.

Mission Moho is still in its infancy, and its success will depend on technological feasibility as well as budgetary considerations. The former may not be an obstacle for too long. Recently developed technology is likely to allow drilling through sea floor that lies at depths of over $4 \mathrm{~km}$ beneath the sea surface: this will enable the relatively thin oceanic crust along a mid-ocean ridge to be targeted. In contrast, current technologies can negotiate a water depth of only about $2.5 \mathrm{~km}$.

Drilling into the mantle is not expected to be cheap by any means. But in all likelihood, Mission Moho will only cost a fraction of what is currently spent on space exploration: compare, for example, the current IODP annual budget of about $\$ 200$ million (Nature $461,578-579$; 2009) with that of NASA (over $\$ 15$ billion for 2009). Peeking into the Earth's interior is closer to home. The voyage is well worth undertaking.

\section{Bridging the biodiversity gap}

\section{As climate change continues to erode biodiversity, the two disciplines need to improve their dialogue.}

The habitat range of more and more species is contracting as a result of global warming. Rising temperatures are forcing birds, butterflies, grasses and trees to higher latitudes and elevations where conditions are more agreeable. However, space and resources are not necessarily adequate for species on the move; human-induced degradation of ecosystems has destroyed many migration avenues, and mountains only stretch so far. Furthermore, a shift in the timing of key events such as flowering, breeding and migration is decoupling the life cycles of a huge number of interacting species. In short, the outlook for biodiversity is bleak.

In response to these challenges, a scientific and practical road map for preserving biodiversity in the face of global change was drawn up at meeting on biodiversity and climate change at the Royal Botanic Gardens, Kew, in London this September. Representatives from the meeting stressed the urgent need to integrate the ecological and climate sciences. Indeed, as James Lovelock pointed out after his talk at the Science Museum in London the following week, the governance of these two disciplines by separate United Nations treaties, the Framework Convention on Climate Change and the Convention on Biological Diversity, is an example of how divided these essentially inseparable disciplines are.

Both the climate and biodiversity communities work hard for the goal of making the planet a better place. But the fastest pathway to a stable climate is not necessarily good for biodiversity preservation. A bare patch of land might look like the ideal location to plant a fast growing forest to mop up carbon dioxide from the atmosphere, but it could also represent one of the few remaining residences for a species on the move. Multiple uses of any given patch of land need to be taken into consideration before deciding how best to use that land. And for that, a dialogue is needed between all the stakeholders. There is no guarantee that ecologists and climate activists will envisage the same solution just because they all fall under the broad umbrella of environmentalists.

Of course, the discussion on biodiversity decline cannot be reduced to the impacts of climate change alone. Other factors that influence ecosystem diversity, such as pollution and land-use change, are far too important. As Georgina Mace of Imperial College London pointed out, conserving biodiversity is a far more complex issue than regulating climate change. Greenhouse gases are a truly global problem, calling for global emissions reductions. Biodiversity losses on the other hand occur essentially at the local level, and an in-depth understanding of individual locations is needed to devise solutions.

Nevertheless, we should at least aim at maintaining an agreeable climate and an acceptable level of biodiversity at the same time. These goals are not in disagreement per se. A little extra thought could go a long way in aligning the interests of ecologists and climatologists. 